Dicle Tıp Dergisi / Dicle Med J (2019) 46 (1) : 11 - 17

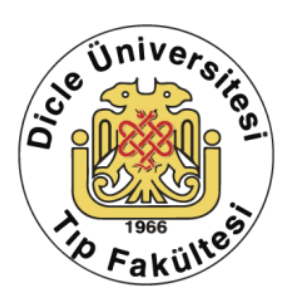

WWW.diclemedj.org

Özgün Araștırma / Original Article

\title{
Tip 1 Diyabetes Mellituslu Çocuklarda Tanı Anındaki Klinik ve Laboratuvar Bulgularının Değerlendirilmesi
}

\author{
Burhan Aras $^{1}$, Alper Akın², Ruken Yıldırım³ ${ }^{3}$ Edip Unal ${ }^{4}$, Yusuf Kenan Haspolat ${ }^{5}$ \\ 1 Dicle Üniversitesi Tıp Fakültesi Çocuk Sağlığı ve Hastalıkları Anabilim Dall, Diyarbakır, Türkiye ORCID: 0000-0002-6833-6462 \\ 2 Dicle Üniversitesi Tıp Fakültesi Çocuk Kardiyolojisi Bilim Dall, Diyarbakır, Türkiye ORCID: 0000-0003-1587-9559 \\ 3 Dicle Üniversitesi Tıp Fakültesi Cocuk Endokrinolojisi Bilim Dall, Diyarbakır, Türkiye ORCID: 0000-0002-9558-3856 \\ 4 Dicle Üniversitesi Tıp Fakültesi Çocuk Endokrinolojisi Bilim Dall, Diyarbakır, Türkiye ORCID: 0000-0002-9809-0977 \\ 5 Dicle Üniversitesi Tıp Fakültesi Çocuk Endokrinolojisi Bilim Dall, Diyarbakır, Türkiye ORCID: 0000-0003-1930-9721
}

Geliş: 04.06.2018; Revizyon: 02.10.2018; Kabul Tarihi: 26.11.2018

Öz

Amaç: Çalışmamızın amacı, Tip 1 Diyabetes Mellitus (T1DM) tanısı alan çocuklarda ilk başvuru bulgularının neler olduğunu belirlemektir.

Yöntemler: Bu çalışma 2013-2016 yılları arasında Dicle Üniversitesi Tıp Fakültesi Çocuk Endokrinoloji ve Çocuk Acil polikliniğine başvuran yeni T1DM tanısı 142 çocuk hasta incelenerek gerçekleştirildi. Retrospektif olarak dosyalardan hastaların sosyodemografik özellikleri, semptom ve laboratuvar bulguları kaydedildi. Elde edilen tüm veriler istatiksel olarak değerlendirildi.

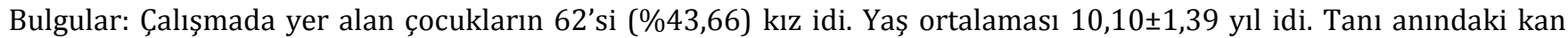
glikoz düzeyi 425,85 $\pm 12,51 \mathrm{mg} / \mathrm{dl}$, HbA1c $\% 13,57 \pm 3,77$ olarak saptandl. Olguların \%47,8'inde glutamat dekarboksilaz antikoru pozitifliği tespit edildi. Hastaların \%18,3'ünde ailede T1DM hikayesi mevcuttu. Hastalar en çok Ocak ayında $(\% 12,6)$ ve Kasım ayında $(\% 11,9)$ tanı aldı. Olguların \%83,8'inde hem poliüri hem de polidipsi bulunurken, \%41,5 olguda bilinç düzey değişikliği ve \%6,3 olguda da koma mevcuttu. Başvuru sırasında hastaların \%43'ünde ketoasidoz mevcut iken, \%48,5'inde ketozis, \%8,5'inde ise sadece hiperglisemi mevcuttu.

Sonuç: Tip 1 DM daha çok adolesan dönemde izlenmektedir. Hastalı̆̆ın en sık başvuru semptomları poliüri ve polidipsidir. $\mathrm{Bu}$ nedenle toplumun poliüri ve polidipsinin T1DM bulguları olabileceği yönünde eğitilmesi gerekmektedir. Toplumun bu konuda bilinçlendirilmesi diyabetin en önemli komplikasyonu olan diyabetik ketoasidoz sıklığının azaltabilir.

Anahtar kelimeler: Tip 1 Diyabetes Mellitus, ketoasidozis, çocuk.

DOI: 10.5798/dicletip.534811

Yazışma Adresi / Correspondence: Alper Akın, Dicle Üniversitesi Tıp Fakültesi Çocuk Kardiyolojisi Bilim Dalı, Diyarbakır, Türkiye e-mail: alperakin1@hotmail.com 


\title{
Evaluation of Clinical and Laboratory Findings at the Time of Diagnosis in Children with Type 1 Diabetes Mellitus
}

\begin{abstract}
Objective: The aim of our study is to evaluation of clinical and laboratory findings at the time of diagnosis in children with Type 1 Diabetes Mellitus (T1DM).

Methods: In this study, 142 children diagnosed with T1DM who were referred to Pediatric Endocrinology Policlinic and Emergency Policlinic of Dicle University Medical Faculty between 2013 and 2016 were evaluated. Retrospectively, the sociodemographic characteristics, symptoms and laboratory findings of the patients were recorded from the files. All the data obtained were evaluated statistically.

Results: Sixty two (43.66\%) of the patients were girls. The mean age was 10,10 $\pm 1,39$ years. The blood glucose level at diagnosis was 425,85 $\pm 12,51 \mathrm{mg} / \mathrm{dl}$ and $\mathrm{HbA} 1 \mathrm{c}$ was $13,57 \pm 3,77$. Anti-Glutamate Decarboxylase (anti-GAD) positivity was detected in $47.8 \%$ of the cases. $18.3 \%$ of the patients had a T1DM story in their family. Patients were diagnosed mostly in January (12.6\%) and November (11.9\%). 83.8\% of cases had both polyuria and polydipsia, 41.5\% had consciousness level change and $6.3 \%$ had coma. Ketoacidosis was present in $43 \%$ of the patients at the time of admission, ketosis in $48.5 \%$ and only hyperglycemia in $8.5 \%$.

Conclusion: Type $1 \mathrm{DM}$ is mostly observed in adolescence. The most common symptoms of the disease are polyuria and polydipsia. For this reason the community needs to be educated that polyuria and polydipsia may have T1DM findings. Awareness of the community in this issue can reduce the frequency of diabetic ketoacidosis, the most important complication of diabetes.
\end{abstract}

Keywords: Type 1 Diabetes Mellitus, ketoacidosis, child

\section{GİRIŞ}

Tip 1 diyabetes mellitus çocukluk yaş grubunda sık görülen, pankreatik beta hücrelerinin yıkımı ile giden ve insülin eksikliği ile sonuçlanan kronik metabolik bir hastalıktır. Olguların büyük kısmında (\%90) beta hücrelerinin otoimmün yıkımı (Tip 1A), az bir kısmında (\%10) ise beta hücrelerinin idiyopatik yıkımı veya yetmezliği söz konusudur (Tip 1B) ${ }^{1}$. T1DM esas olarak çocukluk yaş grubunun hastalığ olup, özellikle 4-6 yaş ve 10-14 yaşlarında pik yapmaktadır ${ }^{2}$. T1DM insidansı ülkeler arasında, hatta aynı ülke içinde farklı bölgelerde ve farklı etnik gruplar arasında değişkenlik göstermektedir. $\mathrm{Bu}$ nedenle hastalığın oluşmasında genetik faktörlerin yanı sıra çevresel faktörlerin de etkili olduğu belirtilmiștir ${ }^{3}$. Ülkemizde 2014 yılında yapılan bir çalışmada T1DM insidansının 0.75/1000 olduğu gösterilmiştir4

Gelişmiş ülkelerde T1DM'nin en sık başvuru şekli asidoz olmadan gelişen hiperglisemik semptomlardır (poliüri, polidipsi, polifaji, idrar kaçırma vb). Az gelişmiş veya gelişmekte olan ülkelerde ise ketoasidoz ile başvuru sıklığı daha yüksektir².

$\mathrm{Bu}$ çalışmada Dicle Üniversitesi Tıp Fakültesi Çocuk Endokrinoloji ve Çocuk Acil polikliniğine başvuran ve T1DM tanısı konulan çocukların demografik özellikleri ve ilk başvuru esnasındaki klinik ve laboratuvar bulgularının değerlendirilmesi amaçlanmıştır.

\section{YÖNTEMLER}

Bu çalışmada 2013-2016 yılları arasında Dicle Üniversitesi Tıp Fakültesi Çocuk Sağlığı ve Hastalıkları Çocuk Endokrinoloji Polikliniği ve Acil Polikliniği'ne başvuran ve yeni T1DM tanısı alan, 0-18 yaş arasında 142 hasta incelenmiştir. T1DM ile ilişkili olmayan başka bir kronik hastalığı olan hastalar çalışma dışı bırakıldı. Retrospektif olarak hasta dosya kayıtları incelenerek hastaların sosyodemografik özellikleri; poliüri, polidipsi, bilinç düzey değişikliği ve koma gibi semptom ve bulgular, Glikolize Hemoglobin A1c (HbA1c), C-peptit, 
kan şekeri, çölyak hastalığının tespiti için bakılan doku transglutaminaz immunglobulin A değerleri, kan bikarbonat (HCO3) ve parsiyel karbondioksit basıncı (PCO2), serum sodyum, potasyum ve Anti glutamik asit dekarboksilaz (Anti GAD) antikor düzeyleri ile diğer laboratuvar bulguları kaydedildi. Tanı anındaki klinik tablo hiperglisemi, ketozis ve ketoasidoz olarak sınıflandırıldı. Başvuru esnasında diyabetik ketoasidoz (DKA) tanısı ve sinıflandırılması ISPAD 2014 kılavuzu temel alınarak yapıldı ${ }^{5}$. Rastgele bakılan kan glukoz değeri $>200 \mathrm{mg} / \mathrm{dl}$, kan gazında $\mathrm{pH}<7.30$, HCO3 <15 mmol/L ve idrar analizinde idrar ketonu pozitif olan olgular DKA olarak kabul edildi. DKA tanısı konulan hastalar kan gazı sonucuna göre hafif, orta ve ağır olmak üzere üç gruba ayrıldı. Kan gazında $\mathrm{pH}$ 7.2-7.3 veya HCO3 10-15 mmol/L ise hafif DKA, pH 7.1-7.2 veya HCO3 5-10 mmol/L ise orta DKA ve $\mathrm{pH}<$ 7.1 veya $\mathrm{HCO} 3<5 \mathrm{mmol} / \mathrm{L}$ ise ağır DKA olarak kabul edildi. Tanı anında açlık plazma glukoz düzeyi $126 \mathrm{mg} / \mathrm{dl}$ ve üzerinde, kan ve idrar ketonu negatif, kan gazında asidoz saptanmayan hastalar hiperglisemi; plazma glukoz düzeyi $126 \mathrm{mg} /$ dl ve üstü, kan ve idrar ketonu pozitif ve kan gazında asidoz olmayan hastalar ketozis olarak sinıflandırıldı. Hastalar tanı yaşlarına göre 5 yaş ve altı, 6-10 yaş ile 10 yaş ve üstü olarak sinıflandırıldı. Bilincin tam kaybı durumunda "koma", bilinçteki değişikliklerin diğer tüm şekilleri için (letarji, somnolans, konfüzyon ve dezoryantasyon) "bilinç düzeyi değişikliği" tanımlaması kullanıldı.

Çalışmada toplanan verilerin analizi, istatistiksel yazılım paketi SPSS 23 (Statistical Package for the Social Sciences - IBM $®$, Chicago, IL, USA) istatistik programı kullanılarak yapıldı. Değişkenlerin normal dağılım gösterip göstermediği görsel (histogram) ve analitik yöntemler (Kolmogorov-Simirnov test) kullanilarak değerlendirildi. Normal dağılım gösteren değişkenler ortalama $\pm \mathrm{SD}$, normal dağılım göstermeyen değişkenler ise ortanca (minimum-maksimum) değerler verilerek gösterildi. Bağımsız grupların karşılaştırılmasında Student-t testi kullanıldı. Oranla belirlenen değişkenlerin istatistiksel analizleri ki-kare testi ile yapıldı. $\mathrm{P}<0,05$ istatistiksel değerlendirmede anlamlı kabul edildi.

Çalışmaya Dicle üniversitesi Tıp Fakültesi girişimsel olmayan klinik araştırmaları etik kurulundan yazılı onay (16-12-2016/No:340) alındıktan sonra başlandı.

\section{BULGULAR}

Çalışmaya alınan 142 hastanın 62'si $(\% 43,66)$ kız, 80'i $(\% 56,33)$ erkek idi. Cinsiyet açısından anlamlı fark saptanmadı $(\mathrm{p}=0,456)$. Tanı anındaki yaş ortalaması 10,10 $\pm 1,39$ yıl olarak saptandı (2 gün-18 yaş). Çalışmaya katılan olguların 26'sinda (\%18,3) ailede T1DM öyküsü bulunurken, 116'sında (\%81,7) ailede T1DM öyküsü olmadığı tespit edildi. Hastaların sosyodemografik özellikleri tablo 1'de özetlenmiştir.

Tablo 1:Hastaların sosyodemografik özellikleri

\begin{tabular}{|cl|}
\hline Hasta sayısı & n: 142 \\
\hline Kız & $62(\% 43,66)$ \\
Erkek & $80(\% 56,33)$ \\
Ortalama tanı yaşı (yıl)* & $10,10 \pm 1,39$ \\
Ailede Tip 1 Diyabetes mellitus varlığı & $26(\% 18,3)$ \\
\hline
\end{tabular}

Değerler sayı (yüzde) ve *ort. \pm SD (dağılım) olarak verilmiştir.

Hastalar yaşlarına göre 3 gruba ayrıldığında 28 i $(\% 19,2) 5$ yaş ve altında yer alırken, 47 'si $(\% 33,10)$ 6-10 yaş aralığında ve 67'si $(\% 47,18)$ 10 yaş ve üstünde yer alıyordu. Tanının mevsimlere göre dağılımına bakıldığında hastaların 40’ı $(\% 28,2) \quad \mathrm{kiş,} \mathrm{35'i} \quad(\% 24,7)$ sonbahar, 34'ü $(\% 23,8)$ ilkbahar ve 33'ünün $(\% 23,3)$ yaz aylarında başvurduğu belirlendi. Çalışmaya alınan çocukların tanı aldığı aylar incelendiğinde; en çok \%12,68'lik oran ile Ocak ayında; daha sonra \%11,97'lik oran ile Kasım, $\% 8,45$ lik oran ile Şubat, Haziran, Ağustos ve Eylül aylarında tanı aldıkları tespit edildi (şekil1). 


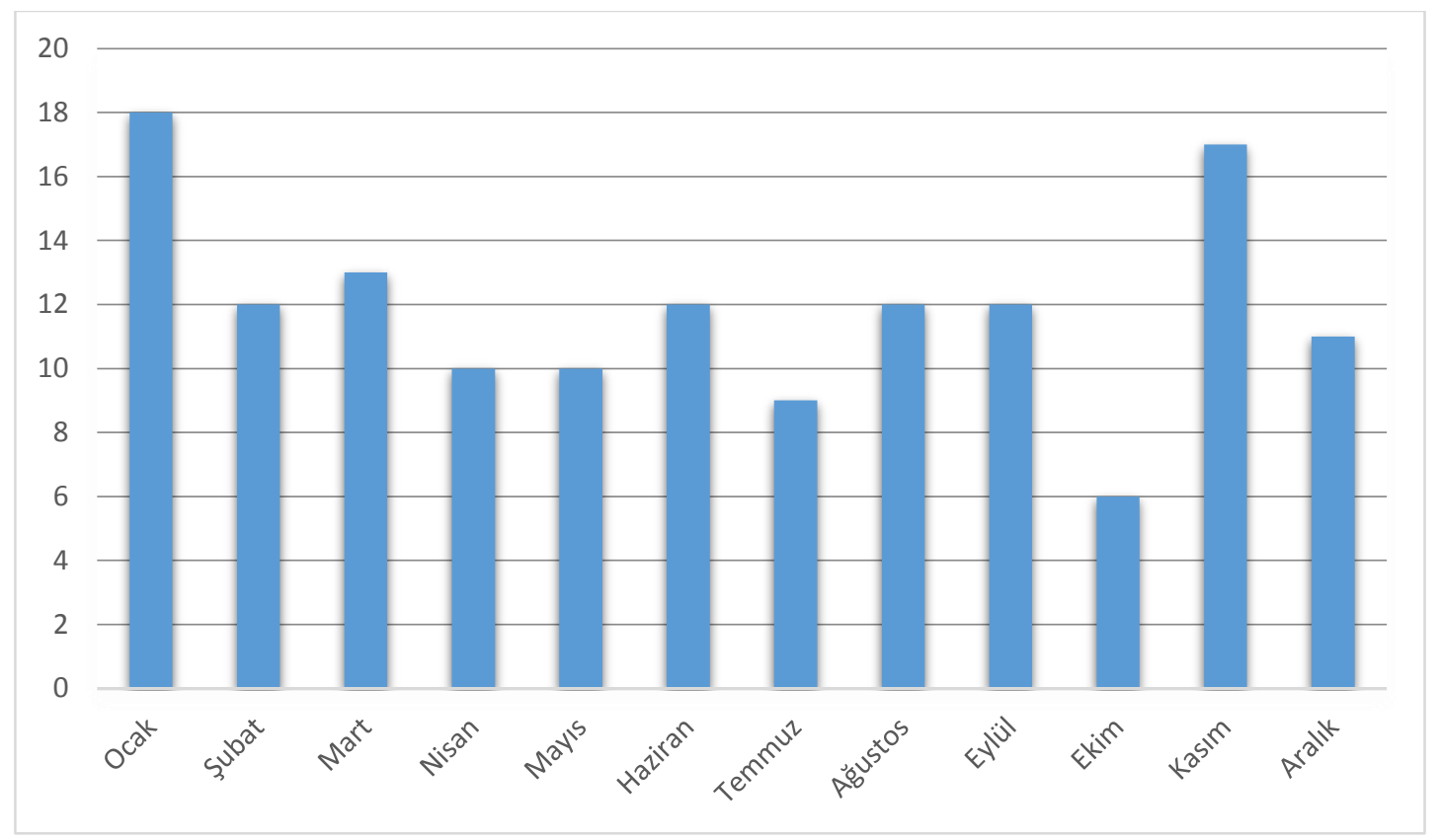

Şekil 1. Aylara göre yeni tanı alan hasta sayıları.

Çalıșmaya alınan hastaların 119'unda $(\% 83,8)$ hem poliüri hem polidipsi bulunurken, 59'unda $(\% 41,5)$ bilinç düzey değişikliği, 9'unda $(\% 6,3)$ koma saptandı. Tanı esnasındaki laboratuvar verileri incelendiğinde; ortalama serum glukozu $425,85 \pm 12,51 \mathrm{mg} / \mathrm{dl}$, serum C-peptit düzeyi $0,82 \pm 0,18 \mathrm{ng} / \mathrm{ml}, \mathrm{HbA1c}$ değeri $13,57 \pm 3,77$, kan gazında PH 7,26 $\pm 0,15$, PCO2 $29,88 \pm 11,39 \mathrm{mmHg}, \mathrm{HCO} 316,17 \pm 6,40 \mathrm{mmol} / \mathrm{L}$ saptandı. Başvuru esnasında; olguların 61'inde (\%43) ketoasidoz, 69'ında $(\% 48,5)$ ketozis ve 12 'sinde $(\% 8,5)$ ise sadece hiperglisemi mevcuttu. DKA ile başvuran olguların 27'sinde $(\% 44,3)$ hafif, 12'sinde $(\% 19,7)$ orta ve 22'sinde (\%36) ağır DKA tablosu mevcuttu. DKA ile başvuran hastaların ortalama HbA1c'si $\% 14,6 \pm 2.7$, DKA ile başvurmayan hastaların HbA1c'si ise \%13,3 $\pm 3.5 \mathrm{mg} / \mathrm{dl}$ olup, aradaki fark istatiksel olarak anlamlı idi ( $\mathrm{p}=0.026)$ Ortalama serum sodyum düzeyi $132,39 \pm 4,49$ $\mathrm{mmol} / \mathrm{L}$, potasyum düzeyi $4,16 \pm 0,61 \mathrm{mmol} / \mathrm{L}$ olarak tespit edildi. Diyabet gelişiminin patogenezinde rolü olduğu öne sürülen antiGAD antikor düzeyi $68(\% 48)$ hastada pozitif saptanırken, çölyak hastalığı için bakılan doku transglutaminaz IgA antikoru $15 \quad(\% 10,5)$ hastada pozitif saptandı. Hastaların tanı esnasındaki semptom ve laboratuvar bulguları tablo 2'de özetlenmiştir.

\section{TARTIŞMA}

Bu çalışmada, T1DM tanısı alan çocuklarda ilk başvuru bulguları ve hastaların demografik özellikleri araştırılmıştır. T1DM çeşitli çalışmalarda cinsiyet açısından farklı sıklıklar göstermektedir. Hastalığın daha sık olduğu Norveç ve Finlandiya'da erkeklerde sıklığın daha yüksek olduğu bildirilirken; Polonya ve İsrail gibi sıklığın daha düşük olduğu ülkelerde ise kızlarda daha sık olarak bildirilmiştir6. Kandemir ve arkadaşları ${ }^{7}$ T1DM'un erkek ve kızlar arasındaki sıklığının benzer olduğunu bildirmiştir. Hatun ve arkadaşlarının ${ }^{8}$ ise hastalığın erkek ve kızlarda benzer oranda görüldüğünü bildirmişlerdir. Çalışmamızda benzer bir şekilde olgularımız arasında cinsiyetler açısından anlamlı bir fark bulunmadı $(\mathrm{p}=0,456)$. Çalışmamızda bulunan hastaların \%56,33’ü erkek, \%43,66`sı kız idi. 
Tablo 2: Tanı anındaki semptom ve laboratuvar bulguları

\begin{tabular}{|ll|}
\hline & $\mathbf{n}(\%)$ \\
\hline Semptom & $119(\%$ \\
Poliürri & $83,8)$ \\
Polidipsi & $119(\%$ \\
Bilinç düzey değişikliği & $83,8)$ \\
Koma & $59(\% 41.5)$ \\
Laboratuvar & $9(\% 6,3)$ \\
PH* & \\
PCO2(mmHg)* & $7,26 \pm 0,15$ \\
HCO3(mmol/L)* & $29,88 \pm 11,39$ \\
Serum sodyum düzeyi (mmol/L)* & $16,17 \pm 6,4$ \\
Serum potasyum düzeyi (mmol/L) * & $132,39 \pm 4,49$ \\
Anti-GAD Antikoru pozitifliği & $4,16 \pm 0,61$ \\
Açlık kan şekeri (mg/dl)* & $68(\% 47,8)$ \\
C-peptit (ng/ml) * & $425 \pm 12,51$ \\
\hline
\end{tabular}

Değerler sayı (yüzde) ve *ort. \pm SD (dağılım) olarak verilmiştir.PCO2:parsiyel karbondioksit basıncı, GAD: glutamik asit dekarboksilaz, HCO3:bikarbonat, $\mathrm{HbA} 1 \mathrm{C}$ :glikozile hemoglobin $\mathrm{C}$, $\mathrm{PH}$ : power of hydrogen

Çalışmamıza alınan çocukların ortalama yaşları $10,10 \pm 1,39$ yll olarak saptanmıştır ve bu çocukların \%47'sinin 10 yaş ve üzerinde $(14,19 \pm 2,41$ yll $)$ yer aldığı tespit edilmiştir. Kandemir ve arkadaşlarının ${ }^{7}$ İç Anadolu Bölgesi ağırlıklı, Türkiye'nin farklı bölgelerinden gelen ve 1969'dan 1991'e kadar izlenen 477 olgudaki epidemiyolojik çalışmasında, diyabet tanı yaşı pikinin 12-14 yaş olduğu bildirilmiştir.

Gül ve arkadaşlarının ${ }^{9} 2006$ yılında yaptıkları retrospektif çalışmada; olguların \%3,4'ünün birinci derece akrabasında diyabet hastalığına (Tip 1 veya Tip 2) rastlandığı bildirilmiștir. Çalışmamıza katılan çocukların \%18,3'ünde ailede T1DM öyküsü mevcuttu. Çalışmamızdaki oran Gül ve arkadaşlarının ${ }^{9}$ buldukları orandan daha yüksektir. Bunun, çalışmamızın akraba evliliğinin sık olduğu bir bölgeyi kapsamasına bağlı olduğunu düşünmekteyiz. Ancak retrospektif bir çalışma olması nedeniyle hastalarımızın anne-babaları arasındaki akrabalık oranlarına ilişkin sağlıklı verilere ulaşılamamıștır. $\mathrm{Bu}$ nedenle çalışmamızda saptanan ailede T1DM saptanma sıklığının yüksek olmasının başka çalışmalarla desteklenmesi ve irdelenmesi gerekmektedir.

Tip 1 DM farklı mevsimlerde farklı sıklıkta görülmektedir ve sıklıkla sonbahar ve kış aylarında tanı konulmaktadır ${ }^{10,11}$. Çalışmalarda ilk başvuru mevsiminin sıklıkla kış mevsimi olduğu ve bu dağılımın kış mevsiminde viral infeksiyon sıklığındaki artış ile ilişkili olduğu bildirilmiştir ${ }^{12,14}$. Güven ve arkadaşlarının ${ }^{12}$ yaptıkları bir çalışmada, Samsun'da T1DM'li çocukların sıklıkla sonbahar ve kış aylarında tanı aldığı bildirilmiştir. Elazığ'da yapılan bir çalışmada T1DM tanısının sıklıkla kış mevsiminde konulduğu; sonbahar ve ilkbahar aylarında ise daha az tanı konulduğu bildirilmiştir ${ }^{13}$. Sağlam ve arkadaşları ${ }^{14} 2008$ yılında yaptıkları araştırmada T1DM'li hasta tanısının üç ayda (Ocak, Şubat ve Mart) zirve yaptı̆̆g; ikinci zirveyi ise sonbaharda (Eylül, Ekim ve Kasım ayları) yaptığını bildirmişlerdir. Şimşek ve arkadaşları ${ }^{15}$ ise olguların \%58'nin kıș, \%20'inin ilkbahar, \%14'ünün yaz, \%8'inin sonbahar mevsiminde tanı aldığını bildirmiştir. Çalışmamızdaki hastaların hastaneye başvuru mevsimi yönünden değerlendirilmesinde istatistiksel olarak anlamlı fark saptanmamıştır.

Çocuklarda diyabet semptomları genellikle akut olarak başladığından tanı daha kolay konulabilmektedir. Sik klinik bulgu olan poliüri, kan glukoz düzeyinin renal eşiği aşması ile ortaya çıkar ${ }^{16,17}$. Çocuklarda diyabetin sık başvuru bulgu ve semptomları poliür ve polidipsi, halsizlik, yorgunluk ve kilo kaybıdır ${ }^{16,18}$. Çalışmamızda yeni tanı T1DM'li hastalarda en sık rastlanan yakınmalar sırasıyla poliüri, polidipsi, DKA, bilinç düzeyi değişikliği ve komadır._Çocukluklardaki T1DM nedeniyle ölümlerde en sık neden DKA ve bunun sonucunda gelișen beyin ödemidir ${ }^{19-22}$. LévyMarchal ve arkadaşlarının ${ }^{23}$ Avrupa'da yaptıkları çok merkezli çalışmalarında DKA sıklı̆̆ı başvuru anında \%26-40 olarak 
bildirilmiştir. Ayrıca hayat ve sağlıkta yüksek standartları olan ülkelerde DKA tanısıyla başvuru sıklığı daha azdır. Hindistan'da tanı anında DKA saptanma oranı \%66 iken; Almanya'da \%26,3 oranında bildirilmiştir ${ }^{24,25}$. Şimşek ve arkadaşları ${ }^{15}$ T1DM tanısı alan 46 hastanın üçte birinin (\%33) başvuruda DKA tanısı aldığını ve bunların dördünde ise koma saptandığını bildirmişlerdir. Ülkemizde Antalya, Bolu ve Eskişehir'de T1DM'li hastalarda yapılan epidemiyolojik çalışmalarda DKA ile başvuru oranının sırasıyla \%34,8, $\% 39,1$ ve $\% 27,2$ olduğu tespit edilmiştir ${ }^{26-28}$. $\mathrm{Bu}$ çalışmaların hiçbirinde olguların DKA ağırlığı (hafif-orta-ağır) belirtilmemiștir. DKA ile başvuru olgularımızın \%43'ünde mevcut olup, bu hastaların tanı sırasında bakılan HbA1c değerleri anlamlı olarak yüksekti. Hastalarımızdaki DKA oranı Avrupa'dan bildirilen değerlerden daha yüksektir. Ayrıca ülkemizin özellikle batı bölgelerinde yapılan çalışmalardan da daha yüksek olduğu görülmektedir ${ }^{15,26-28}$. Bunun nedeninin çalışmamızın sosyoekonomik düzeyin ülkemiz ortalamasının altında olduğu bir bölgede yapılmasından kaynaklanabileceğini düşünmekteyiz. Ancak bu yüksekliğin nedeninin başka çalışmalarla irdelenmesi gerektiğini düşünüyoruz.

Tip 1 diyabette, hastaların \%80-90'ında T hücresi aracılığı ile pankreas adacık beta hücrelerinde yıkım ortaya çıkar. Bu yıkıma neden olan birçok antikor tespit edilmiştir, fakat klinik olarak tespit edilebilen altı antikor bulunmaktadır; bu antikorlar anti-GAD, IAA, ICA, anti-tirozin fosfataz antikor (IA-2A), insülinoma ile ilişkili $2 \beta$ otoantikor (IA-2 $\beta$ ), çinko transporter antikor (ZnT8A)'dur. Kong ve arkadaşları $^{29} 2013$ yılında 86 tip 1 diyabetli hastada yapılan çalışmada tanı anında antikor pozitifliği bakılmış ve hastaların \%66,2'inde anti-GAD, \%54,1'inde ICA ve \%35,6'inda IAA pozitif olarak tespit etmiștir. Demiral ve arkadaşlarının $^{28} \quad 86$ hastayı içeren çalışmalarında hastaların \%53,4'ünde anti-
GAD, \%37,2'sinde ICA ve \%26,7'sinde IAA pozitif saptanmıştır. Bizim çalışmamızda sadece anti-GAD antikoru bakıldı ve hastaların $\% 47,8$ 'inde pozitif saptanarak literatür bulgularıyla benzer olduğu gösterilmiştir.

\section{SONUÇ}

T1DM sık görülen ve önemli metabolik sorunlara yol açan bir hastalıktır. Hastalık adolesan dönemde daha sık görülmekle beraber küçük yaşlarda da görülebilir. DKA en önemli komplikasyonlarından biridir, bu komplikasyonu en aza indirmek için toplum poliüri ve polidipsi gibi sık görülen semptomların T1DM'nın semptomları olabileceği konusunda bilinçlendirilmelidir. Aile öyküsünün yüksek olması nedeniyle DM tanılı hastaların aile bireyleri öncü semptomlar konusunda bilgilendirilmelidir. Ülkemizde sık görülen T1DM'un epidemiyolojik özelliklerinin daha iyi anlaşılması için daha çok sayıda çalışmaya ihtiyaç vardır.

Çıkar Çatışması Beyanı: Yazarlar çıkar çatışması olmadığını bildirmişlerdir.

Finansal Destek: Bu çalışma her hangi bir fon tarafından desteklenmemiștir.

Declaration of Conflicting Interests: The authors declare that they have no conflict of interest.

Financial Disclosure: No financial support was received.

\section{KAYNAKLAR}

1. Atkinson, M. A. and G. S. Eisenbarth, Type 1 diabetes: new perspectives on disease pathogenesis and treatment. Lancet. 2001; 358: 221-29.

2. Vurall $D$, Kandemir N. Tip 1 diabetes mellitus. In: Cinaz P, Darendeliler F, Akıncı A, Özkan B, Dündar BN, Abacı A, Akçay T(eds). Çocuk Endokrinolojisi(4. Baskı). Pediatrik Endokrinolojisi ve Diyabet Derneği Yayınları, İstanbul: Nobel Tıp Kitapevleri, 2014; 399-452.

3. Forouhi NG, Wareham NJ. Epidemiology of diabetes. Medicine (Abingdon). 2014; 42: 698-702.

4. Handelsman Y, Bloomgarden ZT, Grunberger G, et al. American Association of Clinical Endocrinologists and American College of Endocrinology Clinical Practice Guidelines for Developing a Diabetes Mellitus Comprehensive Care Plan-2015. Endocr Pract. 2015; 21:1: 1-87. 
5. Wolfsdorf JI, Allgrove J, Craig ME, et l. ISPAD Clinical Practice Consensus Guidlines 2014.Diabetic ketoacidosis and hyperglycemic hyperosmolar state. Pediatric Diabetes. 2014; Suppl 20: 154-79.

6. Ryan C, Vega A, Drash A. Cognitive deficits in adolescents who developed diabetes early in life. Pediatrics. 1985; 75: 921-7.

7. Kandemir N, Açıgöz E, Yordan N. The Epidemiology of Diabet Onset İnsulin Dependent Diabetes Mellitus in Turkish Children: A Retrospektive Analysis of 477 Cases. Turk J Pediatr. 1994; 36: 191-5.

8. Hatun Ş, Teziç T. Ankara'daki Okul Çocuklarında Tip 1 Diabet Prevalansı. Çocuk Sağlığı ve Hastalıkları Dergisi. 1996; 39: 465-472.

9. Gül A. Tip1 Diabetes Mellituslu Çocuk ve Adolesan Hastaların Retrospektif Olarak Değerlendirilmesi. S.B. İstanbul Bakırköy Kadın Doğum ve Çocuk Hastalıkları Eğitim Araştırma Hastanesi. Uzmanlık Tezi. İst. 2006.

10. International Diabetes Federation. Diabetes Atlas. 6th edition, 2013. http://www.idf.org/diabetesatlas.

11. Green A, Sjolie A.K, Eshoj O. Trends in the epidemiology of IDDM during 1970-2020 in Fyn County, Denmark. Diabetes Care. 1996; 19: 801-6.

12. Güven A, Aydın M. Beş yaşından önce tip 1 diyabetes mellitus tanısı alan çocuklarda etiyopatogenezde rol alan faktörler. Çocuk Sağlığı ve Hastalıkları Dergisi. 2005; 48: 295-300.

13. Taşkın E, Yılmaz E, Kılıç M, ve ark. İnsüline Bağımlı Diyabetes Mellitusun Epidemiyolojik Özellikleri. FÜ Sağ Bil Derg. 2007; 21: 75-9.

14. Sağlam H, Eren E, Çakır ED, ve ark. Diyabetik ketoasidoz ile başvuran çocukların klinik ve labaratuvar özellikleri. Journual of Current Pediatrics. 2008; 6: 94-8.

15. Şimşek E, Karabay M, Kocabay K. Batı karadeniz bölgesinde yaşayan çocuklarda insüline bağımlı diyabetes mellitusun epidemiyolojik özellikleri. Türk Pediatri Arşivi. 2003; 38: 216-22.

16. Alemzadeh R, Wyatt DT. Diabetes Mellitus. In: Behrman RE, Kliegman RM, Jenson HB (eds). Nelson Textbook of Pediatrics. 17 edition. Pennsylvania: Elsevier Saunders; 2004. p.1947-72.

17. ISPAD Clinical Practice Consensus Guidelines 20062007. Assessment and monitoring of glycemic control in children and adolescents with diabetes. Pediatric Diabetes. 2007; 8: 408-18.
18. Saka HN. Diabetes Mellitus. In: Günöz H, Öcal G, Yordam N, Kurtoğlu S (eds). Pediatrik Endokrinoloji (1.Baskı). Pediatrik Endokrinoloji ve Oksoloji Derneği Yayınları, Ankara: Kalkan Matbaacılık; 2003. p.415-55.

19. Sperling MA. Diabetes mellitus. In: Sperling MA. (ed). Pediatric Endocrinology (2nd ed). Philadelphia: WB Saunders, 2002: p.323-63.

20. Rosenbloom AL, Silverstein JH. Diabetes in the child and adolescent. In: Liftshitz F. (ed). Pediatric Endocrinology (4th ed). New york: Marcel-Dekker, 2004: p.611-51.

21. Edge JA, Ford-Adams MA, Dunger DB. Causes of death in children with insulin dependent diabetes 1990-96. Arch Dis Child. 1999; 81: 318-23.

22. Rosenbloom AL, Winter WE, Escobar O, Diabetes Mellitus. In: Lifshitz F, (ed.), Pediatric Endocr. 5th edition. New York: Informa Health Care 2007; 57-202.

23. Lévy-Marchal C, Patterson CC, Gren A. Geographical variation of presentation at diagnosis of type 1 diabetes in children: The EURODIAB Study. Diabetologia. 2001; 44(Supp 3): 75-80.

24. Neu A, Willasch A, Ehehalt S, et al. Ketoacidosis at onset of type 1 diabetes mellitus in children-frequency and clinical presentation. Pediatr Diabetes. 2003; 4: 7781.

25. Jayashree M, Singhi S. Diabetic ketoacidosis: predictors of outcome in a pediatric intensive care unit of a developing country Pediatr Crit Care Med. 2004; 5: 427-33.

26. Kocabaș A, Aldemir Kocabaș B, Karagüzel G, Akçurin S. Tip 1 diyabetes mellitus olgularımızın antropometrik ve metabolik izlem özelliklerinin değerlendirilmesi. Türkiye Çocuk Hastalıkları Dergisi 2013; 3: 113-118.

27. Aydın H, Andıran N, Buluş D, Yağlı E. Tip 1 Diyabetes Mellituslu Hastaların Klinik, Laboratuvar, Sosyokültürel ve Demografik Özellikleri. Türkiye Çocuk Hast Dergisi 2016; 2: 112-9.

28. Demiral M, Binay Ç, Şimşek E. Eskişehir ilinde tip 1 diyabetes mellitus tanısı ile izlenen hastaların epidemiyolojik özellikleri. Çocuk Sağlığı ve Hastalıkları Dergisi. 2016; 59: 14-20.

29. Kong YH, Kim MS, Lee DY. Comparison of the prevalance of islet autoantibodies according to age disease duration in patients with type 1 diabetes mellitus. Ann Pediatr Endocrinol Metab. 2013; 18: 6570. 